\title{
Morphological and molecular characterization of Italian emmer wheat accessions
}

\author{
Mario Augusto Pagnotta*, Linda Mondini \& Maroun Fandy Atallah \\ Department of Agrobiology and Agrochemistry, University of Tuscia, Via San Camillo de Lellis, 01100 Viterbo, \\ Italy (*author for correspondence: e-mail: pagnotta@unitus.it)
}

Received 23 November 2004; accepted 10 June 2005

Key words: ancient wheat, emmer wheat, EST, hulled wheat, molecular markers, Triticum dicoccum

\begin{abstract}
Summary
The characterization of 39 Italian ecotypes and cultivars of Triticum turgidum L. spp. dicoccum Shrank ex Schübler (emmer wheat) was performed utilizing agro-morphological and molecular tools. Emmer wheat is a hulled species which grows wild in the Near East and is still cultivated in the Mediterranean Basin. Due to its characteristics, in Italy it is cultivated mainly in marginal lands of central and southern Italy, where local varieties, adapted to the natural environment where they originated, are used. Emmer wheat cultivation has been drastically reduced during the last century as a consequence of its low yield. Nevertheless, more recently, its agronomic and nutritive values, together with its use in health food products, made its cultivation economically viable in the marginal lands with a parallel increase of the cultivated area which is now more than 2000 ha.

In the present paper the results of morphological evaluation, carried out in an experimental field in central Italy using a randomized block design with three replications, and molecular characterization are reported. The analysed material showed distinctive molecular traits and the existence of a huge amount of diversity not only between varieties, but also within them. When the accessions were clustered utilizing their genetic distance, the clusters were not always in agreement with the accessions origins. The obtained results gave information that can be useful for: (i) future registration of material, (ii) germplasm conservation and (iii) use of this valuable source of emmer germplasm for future breeding programmes.
\end{abstract}

\section{Introduction}

The hulled wheats are species that form a bridge between cultivated (bread and durum) and wild wheat. Their spikes are not fragile, but they are hulled. Moreover, they were the first domesticated wheat species. There are hulled wheats on all possible wheat polyploidy levels: diploid $(2 \times)$, tetraploid $(4 \times)$ and hexaploid $(6 \times)$.

At the diploid level Triticum monococcum L. ssp. monococcum (einkorn wheat) is the cultivated species derived from T. monococcum L. ssp. aegilopoides (Link) Thell. according to van Slageren (1994), or spp. boeoticum (Boiss) according to Mac Key's (1975) taxonomic classification. Recent molecular evidence has shown a monophyletic origin of $T$. monococcum $\mathrm{L}$. ssp. monococcum with domestication occurring about 10,000 years ago in the southeast of Turkey (Heun et al., 1997; Salamini et al., 2002). Einkorn wheat is the donor of the $\mathrm{A}^{\mathrm{m}}$ genome to the hexaploid Triticum zhukovskyi Menabde and Enriczjan $\left(\mathrm{A}^{\mathrm{t}} \mathrm{A}^{\mathrm{t}} \mathrm{A}^{\mathrm{m}} \mathrm{A}^{\mathrm{m}} \mathrm{GG}\right)$.

At the tetraploid level Triticum turgidum L. spp. dicoccum Schrank ex Schübler (emmer wheat) is the domesticated form derived from spp. dicoccoides (wild emmer wheat), and from it the ssp. durum (Desf) Husn. (durum wheat) originated. A single gene, the $\mathrm{Q}$ factor localized on chromosome 5, controls hulledness, which is the greatest morphological difference between emmer and durum.

At the hexaploid level Triticum aestivum L. spp. spelta (spelt wheat) arose by polyplodization of a cross between $T$. turgidum spp. dicoccoides 